\title{
News from the Board of Editors of UiM/EJU
}

\section{Neuigkeiten beim Herausgebergremium von UiM/EJU}

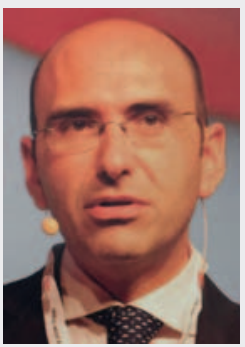

Vito Cantisani

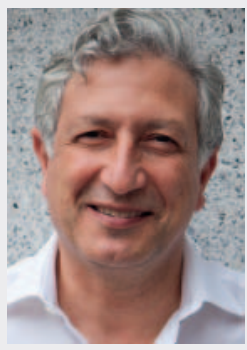

Rabih Chaoui

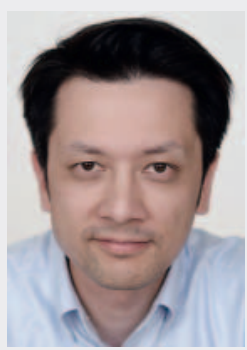

Stefan Meng

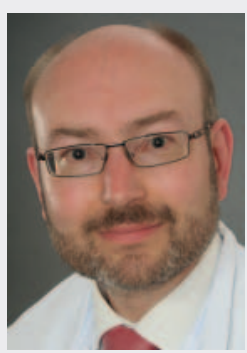

Uwe Walter

\section{Dear Readers,}

Another successful and eventful year for UiM/EJU is drawing to a close. We are happy to report that the number of manuscript submissions continues to be very high, thus allowing us to publish only the best and highest quality papers and resulting in our excellent Impact Factor of 4.389 (IF 2017 as published in June 2018). UiM/EJU is greatly indebted to all of the people who contribute to the journal's ongoing success, including our authors and reviewers, affiliated ultrasound societies and last but not least, you, our loyal readers. The Board of Editors ensures the scientific quality of the journal's articles and we are very pleased that four recognized ultrasound experts have joined the board since the end of last year, namely Vito Cantisani (Rome), Rabih Chaoui (Berlin), Stefan Meng (Vienna) and Uwe Walter (Rostock). Vito Cantisani is the board's new EFSUMB representative as the successor to Michael Bachmann Nielsen, who is continuing his work for the journal as a regular editor. The following provides a short introduction to our new editors.

Dr. Vito Cantisani is the Chairman of Diagnostic and US innovations at Azienda Ospedaliero-Universitaria Policlinico Umberto I, Univ. Sapienza of Rome. He completed a Research Fellowship at BWH, Harvard Medical School, Boston. He is a two-time winner of the EURORAD prize at ECR, the EFSUMB Young Investigator Award, and the Best Scientific Presenter in Head and Neck Session Award at ECR. He received the rank of Assistant Professor and Full Professor at ASN. Dr. Cantisani was secretary and then president of the SIUMB Contrast Media Section, Chairman of EFSUMB EPSC and is currently EFSUMB Chairman of the Publication Committee and SIUMB Elected President. His research is focused on US contrast media in abdominal and non-abdominal applications in correlation with multislice CT, enhanced MRI and US elastography, mainly in the thyroid, testicle, liver, breast and salivary glands. Dr. Cantisani has written or co-written 158 papers published in peer-reviewed international journals, has been an invited lecturer at more than 100 international meetings and has organized several Italian and international congresses. He is also an editor of Ultrasound International Open.

Professor Dr. Rabih Chaoui is a specialist in Obstetrics and Gynecology in Berlin, Germany, with expertise in ultrasound in fetal medicine. Dr. Chaoui was trained at the Obstetrics/Gynecology Departments of the University Hospitals in Berlin and Zurich and was appointed in 2001 as a professor at the Charité's Hospital in Berlin. He has been working since 2004 in a clinical office of the "Center of Prenatal Diagnosis and Human Genetics" in Berlin-Friedrichstrasse. He is a member of several fetomaternal and ultrasound societies and served on their boards for several years. His research focuses on the fetal heart, the fetal brain, the early development of the embryo and fetus, the fetal vascular system examined with color Doppler and on the use of $3 \mathrm{D}$ in fetal medicine. He is the author of more than 200 peer-reviewed articles, some of which have been published in UiM/EJU, and is the author of several books on fetal ultrasound. 
Dr. Stefan Meng is a radiologist in the Kaiser Franz Josef Hospital (Vienna) and in a private office. In his routine clinical work, he is specialized in ultrasound. Additionally, Dr. Meng heads an ex-vivo ultrasound lab at the Center for Anatomy and Cell Biology at the Medical University of Vienna. His clinical and experimental research is focused on neuromuscular and head and neck imaging. He is a member of the board of the Austrian Society for Ultrasound and organizes pre- and postgraduate ultrasound courses.

Professor Dr. Uwe Walter is a neurologist and has been the director of the Neurosonology Lab and Research Group in the Department of Neurology at the University of Rostock since 1999. He is the author of more than 150 peer-reviewed articles and several textbooks and a lecturer on applications of ultrasound of the brain, nerves and muscles in neurodegenerative and movement disorders. His scientific contributions promoted the use of transcranial ultrasound for the early and differential diagnosis of Parkinson's disease and related disorders and established the position control of deep brain stimulation electrodes using ultrasound. His research includes new ultrasound technologies, such as real-time fusion imaging, ultrasound-guided placement of deep brain electrodes, and the combination of Doppler and electrographic techniques. Professor Walter was the recipient of the scientific award of the German Society of Ultrasound in Medicine (DEGUM) in 2004. He serves on several committees of DEGUM, the German Society for Clinical Neurophysiology and Functional Imaging (DGKN), the European Society of Neurosonology and Cerebral Hemodynamics (ESNCH), and the Neurosonology Research Group of the World Federation of Neurology (NSRG-WFN).

We wish the four new editors much success and are excited to see how their enthusiasm and new ideas will help to further our work in the service of ultrasound in medicine.

We hope our readers will continue to enjoy the stimulating and interesting articles in both the present issue and future issues of UiM/EJU.

The Editors and the Publisher 